\title{
Information and Communication Technologies for Supporting Prosumers Knowledge Sharing - Evidence from Poland and United Kingdom
}

\author{
Ewa Ziemba \\ Faculty of Finance and Insurance \\ University of Economics in Katowice \\ ul. 1 Maja 50, 40-287 Katowice \\ Poland \\ ewa.ziemba@ue.katowice.pl
}

\author{
Monika Eisenbardt \\ Faculty of Finance and Insurance \\ University of Economics in Katowice \\ ul. 1 Maja 50, 40-287 Katowice \\ Poland \\ monika.eisenbardt@ue.katowice.pl
}

\author{
Roisin Mullins \\ Faculty of Business and Management \\ University of Wales Trinity Saint David \\ Lampeter, Ceredigion \\ United Kingdom \\ r.mullins@uwtsd.ac.uk
}

\begin{abstract}
Information and communication technologies (ICTs) can enhance the knowledge sharing by lowering temporal and spatial barriers between prosumers and enterprises, and improving access to prosumers' knowledge for enterprises. A major challenge for enterprises involves investing in the appropriate ICTs that help facilitate prosumers' knowledge engagement and knowledge transfer. The purpose of the paper is to indicate which ICTs are currently used and expected to be used by prosumers for knowledge sharing. The reported outcomes are the result of a questionnaire survey that yielded responses from 783 Polish and 171 UK based prosumers. The results indicate the primary ICT choices for use and expected use by Poland and UK based prosumers revealing important differences between these countries. The mobile applications being favored amongst the UK respondents whereas the dedicated enterprise website is the favored ICT amongst Polish respondents. Further, the variety of ICTs provided by enterprises may be too limiting to promote the type of knowledge sharing and communications expected to reassure the prosumers.
\end{abstract}

\section{INTRODUCTION}

K nowledge is currently viewed as a fundamental driver for the commercial success of enterprises and is crucial to their competitive advantage [1]-[4]. Moreover, customer knowledge becomes an essential intangible asset for every line of business [5], leads to better response and respect toward customers [6], [7], makes a contribution toward new and innovative products [8], [9], contributes to the improvement of business value [10], and enhances the competitiveness of businesses [11].

Consumers who share their knowledge with enterprises with the aim of creating values and benefits for enterprises and their own consumption are known as "prosumers," whereas the process in which they share knowledge with enterprises is consistent with the notion of "prosumption" [12]-[17]. In general, prosumption refers to situations in which prosumers share knowledge not only with enterprises, but also with other prosumers to produce things of value for enterprises, and also for themselves.

Given that advances in ICTs have made it easier to share knowledge and these ICT developments have made the world increasing interconnected, many enterprises recognise there are challenges to employ the appropriate ICTs to facilitate knowledge sharing with prosumers. In considering the complexity of prosumption, prosumers' knowledge sharing initiatives and the variety of ICTs, enterprise must often confront these challenging tasks in deciding what type of ICTs to deploy in support of their prosumption initiatives.

The existing studies mostly examine ICTs for knowledge management in enterprises [18]-[23]. Researchers argued that ICTs play an important role in acquiring, codifying, storing, creating, sharing and applying knowledge that can be crucial for effective decision making and control at all levels.

The authors of this paper, following an extensive review of the literature, did not uncover any deep studies to interpret how ICTs support prosumers' knowledge sharing with enterprises. This reveals a need to study the ICTs that should be adopted and used by enterprises to better enable prosumers' knowledge sharing. Therefore, conducting research among prosumers and enterprises should contribute to greater understanding of the use of ICTs for prosumers' knowledge sharing and should help fill the gap in the existing body of knowledge.

In light of the above limitations, this paper focuses on investigating the choice of ICTs supporting prosumers' knowledge sharing in Poland and the UK. Its aim is to indicate the ICTs that are currently used by prosumers in comparison with the preferred ICTs expected to be used by prosumers.

The paper is structured as follows. Section I is an introduction to the subject. Section II states the theoretical background of ICTs for supporting prosumers' knowledge sharing and poses a research question. Section III describes the research methodology. Section IV presents the research findings on ICTs used and expected to be used by prosumers to facilitate knowledge sharing. Section $\mathrm{V}$ provides the study's contributions and limitations, and implications for the findings and considerations for future investigative work.

\section{THEORETICAL BACKGROUND AND RESEARCH QUESTION}

\section{A. Concept of prosumption and prosumer}

The concept of prosumption has emerged from consumption theory. It focuses on the role that can be played by pro-active consumers willing to cooperate with enterprises.

The term 'prosumer' was coined by Toffler [15]. According to him, selected enterprises' tasks (mainly manual 
tasks), previously performed by enterprises' employees, are increasingly performed by consumers in accordance with the do-it-yourself principle, and by implication consumers become co-creators of products and services. Indeed, the terms of prosumption and prosumer have evolved over the years [24], [25]. As a result, modern approaches to prosumption differ greatly from Toffler's proposal. Table 1 presents the characteristics of two approaches to prosumption: Toffler's approach versus the modern approach. The modern approach to prosumption emphasizes the creativity of prosumers, as well as being connected to the value of prosumers' knowledge for enterprises. Enterprises can use their knowledge to attain business goals and, as a consequence, engage prosumers in business tasks.

\section{B. Prosumers' knowledge sharing with enterprises}

Prosumers' knowledge is the most important asset for most sectors engaged in contemporary business and is one of the most important contributors in improving business value and enhancing business performance [6], [27]-[30]. It is categorized into three types [31], [32]:

- Knowledge about prosumers represents both prosumers' needs and requirements; it may encompass characteristics in prosumers' behavior, their demographics and previous purchasing patterns; it may allow an understanding of prosumers' motivation in order to adjust and personalize products' or services';

- Knowledge for prosumers is created to satisfy prosumers' needs; it may include knowledge about enterprises, products and services; it may support prosumers in their buying cycle, impact on prosumers' perception of enterprises and offers, and become the base of knowledge from prosumers; and

- Knowledge from prosumers is created through the prosumers' experience with enterprises; it may embrace ideas, thoughts, reviews, opinions, discussions, advice and rankings that enterprises receive from their prosumers and use them to enhance their products and services.

The sharing of these various kinds of prosumers' knowledge between the prosumers and enterprises is critical in order to produce things that are of value not only for enterprises but also for prosumers. It could be characterized as a process in which prosumers' knowledge is exchanged among prosumers and enterprises. In this process prosumers share what they have learned and transfer what they know to enterprises that have a business interest in it and that have found this new knowledge to be useful for business improvement [33]. In this process the value of knowledge appreciates when it is shared [34].

In this study, the term "prosumers' knowledge sharing" means providing knowledge from prosumers (prosumers" ideas of products developments and creation, thoughts, reviews, opinions, discussions, advice and rankings) to enterprises and other prosumers. This approach is in line with the proposal of Wang and Noe, who distinguished knowledge sharing from knowledge exchange [35].

TABLE I.

NATURE OF PROSUMPTION

\begin{tabular}{|c|c|}
\hline Toffler's approach & Modern approach \\
\hline \multicolumn{2}{|c|}{ Prosumer's role } \\
\hline $\begin{array}{l}\text { Less complex tasks, previously carried out by enterprises' employees } \\
\text { are performed by prosumers }\end{array}$ & $\begin{array}{l}\text { - Sharing knowledge and experience with enterprise } \\
\text { - Participating in enterprise business processes }\end{array}$ \\
\hline \multicolumn{2}{|c|}{ Prosumer's knowledge } \\
\hline $\begin{array}{l}\text { Tasks performed by prosumers were tightly connected with their } \\
\text { manual skills }\end{array}$ & $\begin{array}{l}\text { Prosumers' knowledge is a source of innovative, creative business } \\
\text { solutions, and processes improvement }\end{array}$ \\
\hline \multicolumn{2}{|c|}{ Prosumer's relationship with enterprises } \\
\hline $\begin{array}{l}\text { Static, based on taking over of less important tasks from employees } \\
\text { and performing them themselves }\end{array}$ & $\begin{array}{l}\text { Active, based on collaboration, co-participation, co-design, and co- } \\
\text { creation }\end{array}$ \\
\hline \multicolumn{2}{|c|}{ Prosumers' communication with enterprises } \\
\hline One-way, impeded, most often indirect & Two-way, multi-channel, easy and direct \\
\hline \multicolumn{2}{|c|}{ Main advantages for enterprises } \\
\hline Delegating simple tasks and activities to prosumers & $\begin{array}{l}\text { - Using prosumers' knowledge for achieving business goals } \\
\text { - Following prosumers' needs } \\
\text { - Establishing relationships with prosumers and prosumer-friendly } \\
\text { images of enterprises } \\
\text { - Supporting enterprises' business processes by prosumers' } \\
\text { knowledge }\end{array}$ \\
\hline \multicolumn{2}{|c|}{ Main advantages for prosumers } \\
\hline Self-service accordance with prosumers expectations & $\begin{array}{l}\text { - Expressing own opinions about enterprises and their products } \\
\text { - Adjusting products or services to own needs } \\
\text { - Getting various types of financial and non-financial rewards }\end{array}$ \\
\hline
\end{tabular}

Source: own elaboration on the basis of [26]. 
According to them, "knowledge exchange includes both knowledge sharing (or employees providing knowledge to others) and knowledge seeking (or employees searching for knowledge from others)." It should however be noted that "knowledge sharing" can be also used interchangeably with "knowledge exchange" [36].

\section{ICTs supporting prosumers' knowledge sharing}

Some studies show that ICTs, especially CRM systems [37], Business Intelligence systems [38], and social media [39]-[44] can be used for knowledge management.

Additionally, researchers have examined ICT-tools for knowledge sharing [19], [45]. Jiebing, Bin, and Yongjiang [46] provided a conceptual framework to explore the linking mechanisms between customer knowledge management and ICT-based business model innovation. Studies concerned with the role of ICTs in knowledge sharing enlist such primary technologies as blogs, e-mail systems, e-collaborative systems, e-forums, knowledge repository, instant messaging, audio conferencing, podcasts, video conferencing, and wiki in the context of challenges faced by the practitioners in distributed projects [47] or in the context of Nonaka and Takeuchi's SECI model [48]. The focus of the SECI model on knowledge creation explores the cycle of generating tacit knowledge through to explicit knowledge and recreating tacit knowledge. The knowledge change in the SECI model is summarised as tacit to tacit (Socialization), tacit to explicit (Externalization), explicit to explicit (Combination), explicit to tacit (Internalization) [48], [49].

Only a few of the studies explore the application of social media for sharing customer knowledge. For example Chua and Banerjee [40] presented how Starbucks redefined the roles of its customers through the use of social media by transforming them from passive recipients of beverages to active contributors of innovation. Jalonen [50] explored the interplay between knowledge and emotion in the organisational knowledge creation process in the context of social media. Okazaki et al. [51] found a clear connection among customer engagement, prosumption, and Web 2.0 in a context of service-dominant logic. Moreover, they identified social networks created by prosumers. Based on the literature review, Zembik [52] explored various types of social media and their role as source of knowledge about, for, and from customers. Ziemba and Mullins [32] proposed the conceptual customer stratification framework which explains the stages required by a business to observe customers social media discussions.

\section{D.Research question}

After extensively searching through the literature, it was observed that there is a research gap in the existing body of knowledge related to ICTs used currently by prosumers and expected to be used by them to support prosumers' knowledge sharing. Also there is no research focusing on comparative analysis between less developed countries (like Poland) and better developed (like the UK) in the above mentioned area. In order to bridge the gap this study examines ICTs facilitating Polish and UK based prosumers' knowledge sharing and focuses on addressing the following research question:

RQ: Which ICTs facilitating prosumers' knowledge sharing are currently used and expected to be used by prosumers?

\section{RESEARCH METHODOLOGY}

Research methods included a critical review of the literature, logical deduction, case studies, a survey questionnaire, and statistical analysis. The research process followed the following steps.

The first step. The critical review of existing studies related to "prosumption," "prosumer," "customer," "consumer," "knowledge," "knowledge sharing," "ICT," "information technology" enabled to examine some ICTs supporting prosumers' knowledge sharing. The review embraces five bibliographic databases: Ebsco, ProQuest, Emerald Management, Scopus and ISI Web of Knowledge.

The second step. Interpretation of the case studies reporting prosumers' knowledge sharing informed the identification of the ICTs that are used by prosumers to share knowledge with enterprises.

The third step. An initial pilot survey questionnaire was designed. The questionnaire was divided into two parts. After a few demographics questions all participants were obliged to answer the question: Have you ever assessed or commented on products or companies, proposed products improvements to the companies or designed new products? This question enabled the division of respondents into consumers (not active in this area) and prosumers (active ones). The questionnaire contained questions concerning specified ICTs employed by enterprises to support prosumers' knowledge sharing. The questions were: (1) Which ICTs offered by enterprises have you used to share your knowledge, ideas and proposals about products or enterprises? (2) If you could in a free and unlimited way share your knowledge about products or enterprises, propose ideas of products developments or design new products please indicate which ICTs would you like to use? The former question was directed only to prosumers. The latter was directed to both - prosumers and consumers. Various kinds of ICTs were listed for those questions. For each listed ICTs the respondents could choose one of five responses, according to a 5-point Likert scale: (1) definitely not (never), (2) probably not, (3) I don't know (no answer), (4) probably yes, (5) definitely yes (many times).

The fourth step. In November 2014 the more in-depth pilot survey was conducted in Poland. The purpose was substantive and methodological scrutiny of the questionnaire. To conduct reliability analysis, Cronbach's coefficient alpha was used. Cronbach's alpha for 16 analyzed items was 0.881 . Hinton et al. [53] suggested four different ranges of reliability, i.e. the excellent range ( 0.90 and above), the high 
(0.70-0.90), the high moderate $(0.50-0.70)$ and the low $(0.50$ and below). Thus, it can be concluded that the scale had high reliability and it could be used in the research process. Moreover, substantive scrutiny of the questionnaire enabled the researchers to perform minor changes in order to improve the quality of the questionnaire.

The fifth step. Applying the CAWI (Computer-Assisted Web Interview) method and employing the Polish platform Ankietka.pl, and the English platform Bristol Online Survey (BOS), hosted at the University of Bristol, the survey questionnaires was uploaded to the websites. Data collection took place between the end of December 2014 and March 2015 in Poland, and between February and April 2016 in the United Kingdom. In Poland, the designed sample size was 2.500 people, comprising people of different age, gender, and ICT skills. In the UK the online survey letter and URL was initially posted to 1000 individuals comprising people of different age, gender, and ICT skills, and presented to a random sample of the target population. Using online tools permits contact with an accessible audience as the survey appears on search engine lists due to metatags and appropriate placing of keywords.

After screening the responses and excluding outliers, there was a final research sample of 783 usable, correct and complete questionnaires from Poland and 171 from the United Kingdom. The data was stored in Microsoft Excel format. The demographic analysis of the research sample is presented in Table 2.
The sixth step. As the process of collecting data was completed the reliability was calculated. The Cronbach's alpha coefficient with all 16 items confirmed a high internal consistency (0.882). Additionally, the values of Cronbach's alpha for each item, with the assumption that a given item was deleted, were calculated. The Cronbach's alpha values for the items were between 0.883 and 0.845 . The results showed that the removal of some items would not lead to the improvement of internal consistency among items on the scale. Overall, the original alpha scores with all 16 items show a strong internal consistency and reliability.

The seventh step. In order to answer the research questions the statistical analysis was employed. The descriptive analysis of ICTs was prepared; the mean, median, mode, and distribution of ICTs used and expected to be used by prosumers were calculated.

\section{RESEARCH FINDINGS}

\section{A. ICTs used and expected to be used by prosumers}

In order to answer the research question, detailed analysis concerning ICTs used and expected to be used by prosumers, to share knowledge about products or enterprises, propose ideas of products developments or design new products, was made. The results are presented in Table 3.

"Used ICTs" reflect which ICTs are currently offered by enterprises to prosumers and used by them to share knowledge. It is noticeable that ICTs used by Polish and UK

TABLE II.

DEMOGRAPHIC ANALYSIS OF THE RESEARCH SAMPLE

\begin{tabular}{|c|c|c|c|c|}
\hline \multirow[b]{2}{*}{ Demographic profile } & \multicolumn{2}{|c|}{ Poland } & \multicolumn{2}{|c|}{ United Kingdom } \\
\hline & $\begin{array}{l}\text { Number of } \\
\text { respondents }\end{array}$ & $\begin{array}{c}\text { Percentage of } \\
\text { respondents }\end{array}$ & $\begin{array}{l}\text { Number of } \\
\text { respondents }\end{array}$ & $\begin{array}{c}\text { Percentage of } \\
\text { respondents }\end{array}$ \\
\hline \multicolumn{5}{|l|}{ Gender } \\
\hline female & 599 & $76.5 \%$ & 98 & $57.30 \%$ \\
\hline male & 184 & $23.5 \%$ & 73 & $42.70 \%$ \\
\hline \multicolumn{5}{|l|}{ Age } \\
\hline Builders generation - over 65 years old & 14 & $1.8 \%$ & 8 & $4.68 \%$ \\
\hline Baby-Boomers generation $-51-65$ years old & 35 & $4.5 \%$ & 25 & $14.62 \%$ \\
\hline X generation $-36-50$ years old & 108 & $13.8 \%$ & 67 & $39.18 \%$ \\
\hline Y generation $-21-35$ years old & 369 & $47.1 \%$ & 68 & $39.77 \%$ \\
\hline$Z$ generation - less than 21 years old & 257 & $32.8 \%$ & 3 & $1.75 \%$ \\
\hline \multicolumn{5}{|l|}{ Level of education } \\
\hline higher education & 217 & $27.7 \%$ & 89 & $52.05 \%$ \\
\hline secondary education & 559 & $71.4 \%$ & 75 & $43.86 \%$ \\
\hline less than secondary education & 7 & $0.9 \%$ & 7 & $4.09 \%$ \\
\hline \multicolumn{5}{|l|}{ Place of residence } \\
\hline city with a population of more than 100.000 & 419 & $53.5 \%$ & 96 & $56.14 \%$ \\
\hline city with a population of less than 100.000 & 244 & $31.2 \%$ & 53 & $30.99 \%$ \\
\hline rural area & 120 & $15.3 \%$ & 22 & $12.87 \%$ \\
\hline
\end{tabular}

Source: own elaboration. 
based prosumers varies a lot. Polish prosumers mainly use enterprises' websites (the mean value is 3.72), e-mails (the mean value is 3.52 ), and Internet forums (the mean value is 3.40). UK based prosumers mainly use mobile applications (the mean value is 4.01), Facebook fanpages (the mean value is 3.78), and enterprises' specialized applications (the mean value is 3.59). Interestingly, the Facebook fanpages result for the median and mode values are 4.00 for 'used ICT' for both the UK and Poland prosumers. It means that the majority of prosumers have ticked the answer 'probably yes', so they probably were using these ICTs to share knowledge with enterprises or other prosumers.

It is useful to underline, that differences between the mean values of a number of used ICTs are significant in both countries. The most substantial difference relates to mobile applications - the mean value is 2.56 for Poland, whereas it is 4.01 for UK. Similarly, the mean value of enterprises' specialized applications is 2.40 for Poland, whereas it is 3.59 for the UK. It indicates that UK based prosumers use those ICTs more frequently than Polish ones. The outcomes show that Polish prosumers use only popular information websites more frequently than UK based prosumers. The mean value is 2.82 and the mode value is 4.00 for Poland, whereas the mean value is 2.33 and the mode value is 2.00 for UK. Admittedly, the differences between the mean values are not significant for mobile applications and enterprises' specialized applications. Nonetheless, the mode values analysis shows that the majority of Polish prosumers have chosen the answer 'probably yes', so popular information websites are probably offered to them by enterprises; whereas the majority of UK based prosumers have chosen the answer 'probably not', so these websites are probably offered to them but these are not the preferred prosumer exchange choice.

The overall analysis of used ICTs shows that UK based prosumers use ICTs for knowledge sharing more frequently than Polish ones. In addition, Polish prosumers use mainly standard and well known ICTs, whereas UK based prosumers use the latest kinds of ICTs.

"Expected ICTs" reflect which ICTs are needed by prosumers to share knowledge. The research findings show that UK based prosumers mainly expect to engage using mobile applications. The mean value is 3.74 . The median and mode values are 4.00. Furthermore, they expect to engage directly with enterprises' websites and Facebook fanpages (the mean values are 3.53 in both cases). Polish

TABLE III.

ICTS USED AND EXPECTED TO BE USED BY POLISH AND UK PROSUMERS ENGAGED IN KNOWLEDGE SHARING

\begin{tabular}{|c|c|c|c|c|c|c|c|c|c|c|c|c|}
\hline \multirow{3}{*}{ ICTs } & \multicolumn{6}{|c|}{ 'Used ICTs' } & \multicolumn{6}{|c|}{ 'Expected ICTs' } \\
\hline & \multicolumn{3}{|c|}{ POLAND } & \multicolumn{3}{|c|}{ UK } & \multicolumn{3}{|c|}{ POLAND } & \multicolumn{3}{|c|}{ UK } \\
\hline & 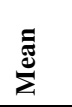 & & $\stackrel{\Xi}{\Sigma}$ & $\sum_{\Sigma}^{\tilde{E}}$ & 㲵 & $\stackrel{8}{\Sigma}$ & $\sum_{\Sigma}^{\tilde{E}}$ & & $\stackrel{\Xi}{\Sigma}$ & 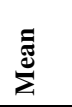 & & $\sum_{\Sigma}^{\stackrel{2}{E}}$ \\
\hline E-mails & 3.52 & 4 & 4 & 3.34 & 4 & 4 & 3.77 & 4 & 4 & 3.29 & 4 & 4 \\
\hline Internet forums & 3.40 & 4 & 4 & 3.33 & 4 & 4 & 3.54 & 4 & 4 & 3.18 & 4 & 4 \\
\hline Enterprises' websites & 3.72 & 4 & 4 & 3.53 & 4 & 4 & 4.00 & 4 & 4 & 3.53 & 4 & 4 \\
\hline Popular information websites & 2.82 & 3 & 4 & 2.33 & 2 & 2 & 3.44 & 4 & 4 & 2.53 & 2 & 2 \\
\hline Industry specialized portals & 2.87 & 3 & 4 & 3.26 & 4 & 4 & 3.57 & 4 & 4 & 3.25 & 4 & 4 \\
\hline Mobile applications & 2.56 & 2 & 1 & 4.01 & 4 & 4 & 3.28 & 4 & 4 & 3.74 & 4 & 4 \\
\hline Enterprises' specialized applications & 2.40 & 2 & 1 & 3.59 & 4 & 4 & 3.43 & 4 & 4 & 3.25 & 4 & 4 \\
\hline File sharing portals & 2.54 & 2 & 1 & 2.96 & 2 & 2 & 3.16 & 3 & 4 & 2.87 & 2 & 2 \\
\hline Facebook fanpages & 3.11 & 4 & 4 & 3.78 & 4 & 4 & 3.38 & 4 & 4 & 3.53 & 4 & 4 \\
\hline Crowdsourcing portals & 1.61 & 1 & 1 & 2.26 & 2 & 2 & 2.34 & 2 & 2 & 2.33 & 2 & 2 \\
\hline Business blogs & 1.98 & 2 & 1 & 2.51 & 2 & 2 & 2.85 & 3 & 4 & 2.64 & 2 & 2 \\
\hline Private blogs & 2.18 & 2 & 1 & 2.24 & 2 & 2 & 2.73 & 3 & 2 & 2.25 & 2 & 2 \\
\hline Online auctions & 2,99 & 3 & 4 & 2,47 & 2 & 2 & 3,07 & 3 & 4 & 2,40 & 2 & 2 \\
\hline Price comparison websites & 2,99 & 3 & 4 & 2,92 & 3 & 4 & 3,38 & 4 & 4 & 2,77 & 2 & 2 \\
\hline Enterprises' helplines/ helpdesks & 2.15 & 2 & 1 & 3.13 & 4 & 4 & 2.52 & 2 & 2 & 3.01 & 3 & 4 \\
\hline Online surveys & 3.16 & 4 & 4 & 2.99 & 3 & 2 & 3.10 & 3 & 4 & 2.89 & 2 & 2 \\
\hline
\end{tabular}

Source: own elaboration. 
prosumers mainly expect to engage via enterprises' websites The mean, median and mode values are 4.00. They also choose e-mails (the mean value is 3.77 ) and industry specialized portals (the mean values is 3.57).

The overall analysis of ICTs presented in Table 3 shows that in the case of Poland all the mean values of "used ICTs" (except for online surveys) are lower than the mean values of "expected ICTs". It may show that ICTs which are currently offered to Polish prosumers by enterprises may not meet their expectations. Thus, Polish prosumers would like enterprises to offer them a greater range of ICTs. It could influence their willingness to share their knowledge with enterprises. In the case of UK based prosumers the majority of the reported mean values for "expected ICTs" are slightly lower than the mean values for "used ICTs" (11 from 16). It may illustrate that ICTs which are currently offered to UK based prosumers by enterprises meet or even slightly exceed their expectations. Four ICTs are expected to be used to a higher degree than are currently used and are referred to as popular information websites, crowdsourcing portals, business blogs and private blogs. Perhaps an indication of a willingness to switch one ICT channel for another one where these ICTs may be seen to be more specific to envelop a critical mass of 'close' engagement and discussion which enhances the prosumers effort. Only one channel that of enterprises' websites reported the same median for expected ICTs and used ICTs. The differences between the mean values are not significant in any case.

In order to compare ICTs used and expected to be used by prosumers of both countries two analyses are presented below. The analyses embrace only these prosumers who ticked (4) or (5) answering the questionnaire questions. It is indicating that they probably or definitely use or expect to use ICTs to share knowledge.

\section{B. ICTs used by prosumers - distribution analysis}

The research findings identify the ICTs used by Polish and UK based prosumers to enable knowledge sharing with enterprises as shown in Figure 1.

Figure 1 shows that there are no significant differences between Polish and UK based prosumers related to standard ICTs used by them, such as e-mails, Internet forums, enterprises' websites, and price comparison websites. Nonetheless, there are significant differences concerning other ICTs used by Polish and UK based prosumers.

The biggest differences pertain to mobile applications (indicated by $88.2 \%$ of UK based prosumers in relation to $33 \%$ of Polish prosumers), enterprises' specialized applications (indicated by $71.1 \%$ of UK based prosumers in comparison with $25.5 \%$ of Polish prosumers), and enterprises' helplines/ helpdesks (indicated by $56.6 \%$ of UK based prosumers in relation to $18.8 \%$ of Polish prosumers). The outcomes show also that only in two cases - which are online auctions and popular information websites, Polish prosumers use them in a considerably greater range then UK.
For example, online auctions were indicated by $46.6 \%$ of Polish prosumers in relation to $25 \%$ of UK based prosumers. Similarly, popular information websites were indicated by $39.7 \%$ of Polish prosumers in relation to $17.1 \%$ of UK based prosumers. Overall the analysis shows that UK based prosumers use and probably engage with UK based enterprises where the choice of ICTs for knowledge sharing is a more extensive range than the Polish enterprise ICT offer.

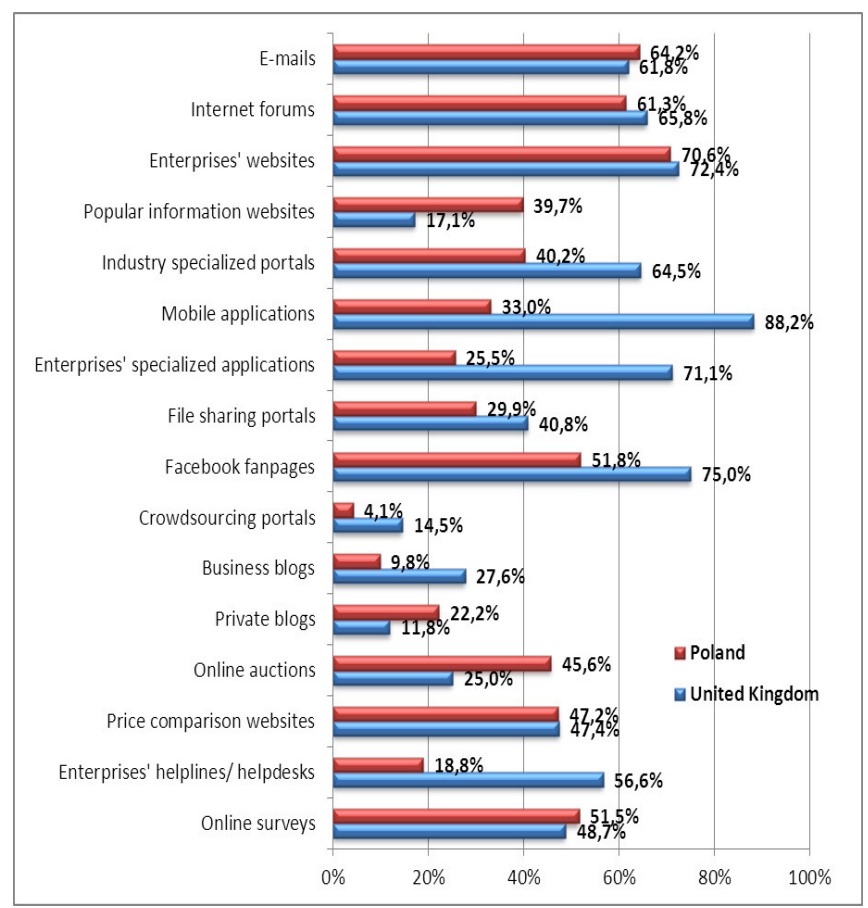

Fig. 1. ICTs used by prosumers for knowledge sharing Source: own elaboration

\section{ICTs expected to be used by prosumers - distribution analysis}

The research findings of ICTs expected to be used by Polish and UK based prosumers for their knowledge sharing with enterprises is shown in Figure 2.

Figure 2 shows that in eleven cases (from a total of 16) Polish prosumers more frequently expect ICTs for knowledge sharing than UK based prosumers. The biggest difference relates to popular information websites indicated by $58.2 \%$ of Polish prosumers and $24.6 \%$ of UK based prosumers. Whereas, UK based prosumers more frequently expect enterprises' helplines/ helpdesks than Polish prosumers. This is indicated by $49.1 \%$ of UK based prosumers and $22.2 \%$ of Polish prosumers. Similarly, mobile applications are expected by $75.4 \%$ of UK based prosumers and $50.1 \%$ of Polish prosumers. The considerable difference relates also to online auctions indicated by $41.3 \%$ of Polish prosumers and $21.6 \%$ of UK based prosumers, as well as to price comparison websites indicated by $55 \%$ of Polish prosumers and $38.6 \%$ of UK based prosumers. 


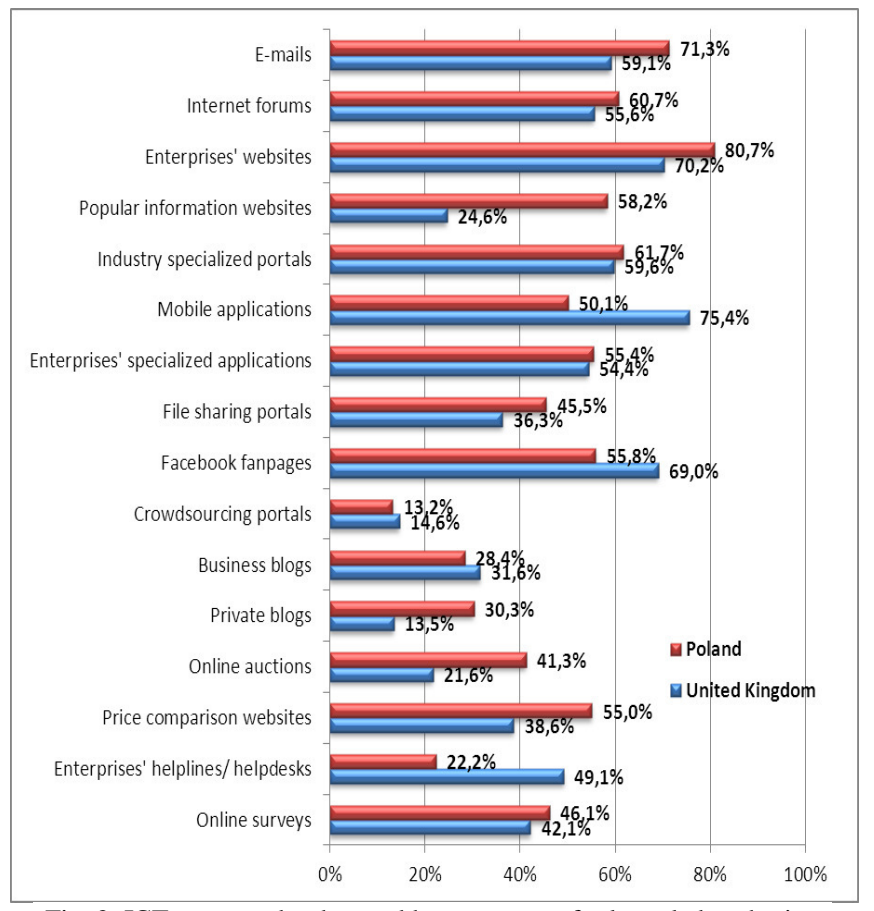

Fig. 2. ICTs expected to be used by prosumers for knowledge sharing Source: own elaboration

Generally, the prosumers usage and expectations of ICTs for knowledge sharing are only slightly different in the UK. It may show that enterprises offer those ICTs for knowledge sharing that are expected by enterprises. Whereas, the prosumers usage and expectations of ICTs for knowledge sharing are significantly different in Poland. It may show that currently the enterprises do not meet their expectation.

\section{DISCUSSION OF FINDINGS}

The trends identified in the demographics breakdown for the Polish and UK based respondents follow a similar pattern to those outlined in Smith [54]. Consistent with other studies females are more inclined to respond to surveys questioning the use and intended use of ICTs for knowledge sharing with enterprises as our findings show for Poland as well as the UK respondents.

There were similarities in the categorization of participants in the age categories, in the case of the builders generation the responses were 1.8\% from Poland and $4.68 \%$ from the UK, and would not be unexpected given the training and technical competences of this generation and their culture of communicating more face-to-face rather than through online questionnaires. Also generation $\mathrm{Y}$ responses were $41.7 \%$ from Poland and $39.77 \%$ from the UK and this age category expect to use devices to communicate online and are comfortable with this mode of communication. These outcomes are consistent with research from authors [55], [56] whose goal was to elaborate critical success factors for ICTs adoption by people in Poland. The overall analysis of outcomes also shows differences between these generations. For generation Y it is self-satisfaction with e-products and e-services delivered by enterprises and public administration that is crucial, whilst for builders generation their awareness of ICTs is critical.

The differences reflected in the categorization of participants presents an interesting breakdown, where generation $\mathrm{X}$ reported Poland responses as $4.5 \%$ whereas $14.62 \%$ for the UK responses since this age range in the UK use technology in the workplace or home, are often selftaught in using technology and commit time to engaging in knowledge sharing. Generation $\mathrm{X}$ in responses from Poland was $13.8 \%$ while UK was $39.18 \%$ and this is a marked difference in responses indicating a possible culture of more accepted online communication in the UK for this age range. Finally generation $\mathrm{Z}$ indicated Poland at $32.8 \%$ whereas UK was only $1.75 \%$, an interesting marked differences in responses and this needs further research to determine if the survey was more visible to this age range in Poland where their use of technology is embedded in their everyday social interactions. However, the research reported [55] indicated that for Polish generation $\mathrm{X}$ the most crucial success factors for ICT adoption is the need to make one's own live easier, whilst for Polish generation $\mathrm{Z}$ it is the financial situation of the household. It may partially explain the difference relating to generation $\mathrm{Z}$ prosumers. Polish prosumers use ICTs to enhance the opportunities of financial benefits or merits.

The educational differences reported between Poland and UK respondents fit well with the categorization of age responses especially as few responses from both countries were from those who are less educated, showing educational attainment may be an indicator for participating in knowledge sharing.

The respondent's place of residence was equally captured for both countries with half of the respondents from both countries living in a city with a population of more than 100.000 , and this is interesting as the greater the chances to communicate offline in larger population centers the more likely the respondents are to use time for online communication, and this is a cultural communication shift noted in other recent studies.

The results indicated no significant differences between Polish and UK based prosumers in their use of standard ICTs, such as e-mails, Internet forums, and websites of enterprises. The most substantial difference in the ICTs used and expected by prosumers relates to mobile applications the mean value is 2.56 for Poland (33\%), whereas it is 4.01 for UK $(88.2 \%)$ and this is consistent with research to support this use of mobile as an enabler of knowledge sharing.

The overall analysis of ICTs used shows that UK based prosumers use ICTs for knowledge sharing more frequently than Polish ones and this may be associated with levels of education achieved as there was almost twice as many UK $(52.05 \%)$ responses than Polish respondents (27.7\%) with higher education attainment.

The findings also show that mobile applications are the 'expected ICTs' needed by UK based prosumers to share 
knowledge, followed by use of Facebook fanpages and enterprises' websites. Whereas, Polish prosumers mainly expect to engage with use of enterprises' websites, followed by e-mails and industry specialized portals. Interestingly, crowdsourcing portals and blogs are those ICTs which, UK based and Polish prosumers, do not expect or cite a preference to use.

The findings also show that Polish prosumers more frequently expect to use ICTs for knowledge sharing than UK based prosumers who have an expectation to use the enterprises' helplines/ helpdesks instead or to complement their online initiated discussions.

A recommendation is that the enterprises need to take consideration of the culture of contemporary communication choices associated with the wide age ranges of prosumers. Finally the enterprises need to embed a comprehensive choice of ICT's particular to their prosumers needs to actively encourage knowledge sharing.

\section{CONCLUSIONS}

\section{A. Research contribution}

This work contributes to existing research on prosumption, especially prosumers' knowledge sharing with the use of ICTs by:

- Indicating the ICTs currently used by prosumers to promote knowledge sharing with enterprises; and

- Indicating the ICTs expected to be used by prosumers to stimulate knowledge sharing with enterprises.

Firstly, this study indicates that mobile application use is expected to a greater degree by UK based prosumers. However, they also expect to use the enterprises' helplines/ helpdesks indicating the diverse expectations and somewhat divergent needs of UK based prosumers and the opportunities this presents to enterprises.

Secondly, the outcomes show that ICTs which are currently offered to UK based prosumers by enterprises meet or even slightly exceed their expectations. However, the prosumers usage and expectations of ICTs for knowledge sharing are significantly different in Poland suggesting that the enterprises do not meet their expectation, and this may result in less engagement in knowledge sharing.

\section{B. Implication for research and practice}

This study can be useful for researchers. They may use this methodology and do similar analyses with different sample groups in Poland, United Kingdom, and other countries; additionally many comparisons between different groups and countries can be made. Moreover, the methodology constitutes a very comprehensive basis for identifying ICTs to support knowledge sharing, both, about prosumers, as well as for and from prosumers, but researchers may develop, verify and improve this methodology and its implementation. In addition, researchers may use these research findings and employ them in studies of enterprises. Their goal could be the analysis of ICTs and the possibilities of adjusting them to the expectations of prosumers.

Moreover, for practitioners, the results of this study can be used to improve activities aimed at prosumption adoption, especially helping them understand which ICTs should be used to support prosumers' knowledge sharing.

\section{Limitations and future research}

As with many other studies, this study has its limitations. The first one was the selection of the survey respondents. Most of them were young people below 35 years old. It is advisable to extend the future research to elderly persons, inter alia prosumers $50+$.

The second limitation was the relatively low number of respondents from United Kingdom in comparison with the number of respondents from Poland. Resulting from the low UK responses and timing of the survey the research will continue in the UK to ensure a higher response rate for deeper analysis. Since the initial results reveal interesting findings the research will continue to generate a higher response rate, and for this reason this paper is rather preliminary, and recognizes the analysis are not to be generalized. Therefore the research will be extended with detailed analysis in further works.

As the third limitation, it is possible to specify a methodological limitation. The research sample embraced only prosumers, not enterprises. It is advisable to extend the research to enterprises. All these above issues should be carefully considered and assimilated in the future works.

\section{ACKNOWLEDGMENT}

This research has been supported by a grant entitled "Transformation of business and public administration by information technology and information systems" from the University of Economics in Katowice, Poland, 2014-2016.

\section{REFERENCES}

[1] A. Jaki and B. Mikuła, Eds., Knowledge - Economy - Society. Managing Organizations: Concepts and Their Applications (in Polish). Cracow: University of Economics, 2014.

[2] J. Kisielnicki, Zarzadzanie i informatyka (in Polish). Warsaw: Placet, 2014.

[3] A. Kowalczyk and B. Nogalski, Zarzadzanie wiedza: koncepcje i narzędzia (in Polish). Warsaw: Difin, 2007.

[4] F.P. Omotayo, "Knowledge Management as an important tool in organisational management: A review of literature," Library Philosophy and Practice (e-journal), Paper 1238, 2015. Available at: http://digitalcommons.unl.edu/libphilprac/1238/.

[5] J. Rowley, "Eight questions for customer knowledge management in e-business," Journal of Knowledge Management, vol. 6(5), pp. 500 511, 2002, http://dx.doi.org/10.1108/13673270210450441.

[6] B. Aghamirian, B. Dorri, and B. Aghamirian, "Effects of customer knowledge management's eight factors in e-commerce," Management Science and Engineering, vol. 7(4), pp. 1-11, 2013.

[7] S.-M. Tseng, "The effect of knowledge management capability and customer knowledge gaps on corporate performance," Journal of Enterprise Information Management, vol. 29(1), pp. 51-71, 2016, http://dx.doi.org/10.1108/JEIM-03-2015-0021. 
[8] D.C. Brabham, "Motivations for participation in a crowdsourcing application to improve public engagement in transit planning," Journal of Applied Communication Research, vol. 40(3), pp. 307328, 2012, http://dx.doi.org/10.1080/00909882.2012.693940.

[9] W. Tsai, M. Tsai, S. Li, and C. Lin, "Harmonizing firms' knowledge and strategies with organizational capabilities," Journal of Computer Information Systems, 53(1), pp. 23-32, 2012.

[10] A.-M. Croteau and P. Li, "Critical success factors of CRM technological initiatives," Canadian Journal of Administrative Sciences, vol. 20(1), pp. 21-34, 2003, http://dx.doi.org/10.1111/ j.1936-4490.2003.tb00303.x.

[11] E.-J. Song and M.-S. Kang, "A study on the platform of knowledge integration for customer feedback in B2C service industry," International Journal of Information and Communication Technology, vol. 8(1), pp. 26-36, 2016, http://dx.doi.org/10.1504/ ijict.2016.073637.

[12] C. Fuchs, "Web 2.0. Prosumption, and Surveillance," Surveillance \& Society, vol. 8(3), pp. 288-309, 2011.

[13] G. Ritzer and N. Jurgenson, "Production, consumption, prosumption: The nature of capitalism in the age of the digital 'prosumer'," Journal of Consumer Culture March, vol. 10(1), pp. 13-36, 2010, http://dx.doi.org/10.1177/1469540509354673.

[14] D. Tapscott and A.S. Williams, Wikinomics: How mass collaboration changes everything. New York: Penguin Group, 2006.

[15] A. Toffler, The Third Wave. New York: Bantam Books, 1980.

[16] C. Xie, R.P. Bagozzi, and S.V. Troye, "Trying to prosume: Toward a theory of consumers as co-creators of value," Journal of the Academy of Marketing Science, vol. 36, pp. 109-122, 2008.

[17] E. Ziemba, "Conceptual model of information technology support for prosumption," in Proc. of Int. Conf. on Management, Leadership and Governance - ICMLG 2013, pp. 355-363. Bangkok University, February 07-08, 2013.

[18] Ł. Osuszek and S. Stanek, "Knowledge management and decision support in adaptive case management platforms," in Proc. of the 2015 Federated Conf. on Computer Science and Information Systems, 2015, pp. 1539-1549, 2015, http://dx.doi.org/10.15439/2015f60.

[19] Ö.G. Bayram and H. Demirtel, "Effect of ICT on information sharing in enterprises: The case of Ministry of Development," in Proc. of European Conf. on Knowledge Management ECKM, Kidmore End: Academic Conferences International Limited, pp. 94-101, Sep. 2014.

[20] Y.-Y. Chen and H.-L. Huang, "Strategic orientation of knowledge management and information technology and their effects on performance," in Proc. of Pacific Asia Conference on Information Systems PACIS 2014, Chengdu, China, 24-28 June 2014.

[21] M.T. García-Álvarez, "Analysis of the effects of ICTs in knowledge management and innovation: The case of Zara Group," Computers in Human Behavior, vol. 51, pp. 994-1002, 2015, http://dx.doi.org/10.1016/j.chb.2014.10.007.

[22] F.N.D Piraquive, V.H.M García, R.G. Crespo, and D. Liberona, "Knowledge management, innovation and efficiency of service enterprises through ICTs appropriation and usage," Lecture Notes in Business Information Processing, vol. 185, pp. 300-310, 2014, http://dx.doi.org/10.1007/978-3-319-08618-7_29.

[23] R. Subashini, S. Rita, and M. Vivek, "The role of ICTs in knowledge management (KM) for organizational effectiveness," Communications in Computer and Information Science, vol. 270, pp. 542-549, 2012, http://dx.doi.org/10.1007/978-3-642-29216-3_59.

[24] M. Izvercianu, S. Seran, and C.F. Buciuman, "Changing marketing tools and principles in prosumer innovation management," European Conf. on Management, Leadership \& Governance, Kidmore End: Int. Limited, pp. 246-255, 2012.

[25] D. Jelonek, C. Stępniak, and T. Turek, "Prosumpcja w regionalnych społecznościach elektronicznych dla potrzeb przedsięwzięć miejskich (in Polish)," in Zeszyty Naukowe Uniwersytetu Ekonomicznego w Katowicach, no. 243, J. Gołuchowski and A. FrączkiewiczWronka, Eds., Katowice: University of Economics, pp. 151-164, 2015.

[26] E. Ziemba and M. Eisenbardt, "Examining prosumers participation in business processes," Online Journal of Applied Knowledge Management, vol. 2(1), pp. 219-229, 2015

[27] A.S. Cui and F. Wu, "Utilizing customer knowledge in innovation: antecedents and impact of customer involvement on new product performance," Journal of the Academy of Marketing Science, pp. 123, March 2015, http://dx.doi.org/10.1007/s11747-015-0433-x.

[28] M.F.A.K. Panni, "CKM and its influence on organizational marketing performance: Proposing an integrated conceptual framework," in Customer-centric marketing strategies: Tools for building organizational performance, H.R. Kaufman and M.F.A.K. Panni, Eds., Hershey: IGI Global, pp. 103-125, 2015 , http://dx.doi.org/10.4018/978-1-4666-2524-2.ch006.

29] M.R. Shihab and A.A. Lestari, "The impact of customer knowledge acquisition to knowledge management benefits: A case study in Indonesian banking and insurance industries," in Proc. of 2014 Int. Conf. on Advanced Computer Science and Information Systems, pp. 301-306, 2014, http://dx.doi.org/10.1109/icacsis.2014.7065867.

[30] N. Taherparvar, R. Esmaeilpour, and M. Dostar, "Customer knowledge management, innovation capability, and business performance: A case study of the banking industry," Journal of Knowledge Management, vol. 3(18), pp. 591-610, 2014, http://dx.doi.org/10.1108/jkm-11-2013-0446.

[31] J.O. Chan, "Big data customer knowledge management," Communications of the IIMA, vol. 14(3), Article 5, 2014, Available at: http://scholarworks.lib.csusb.edu/ciima/vol14/iss3/5.

[32] E. Ziemba and R. Mullins, "Identifying more about customers: the phenomenon of the switch to the knowledge exchange," Journal of Applied Knowledge Management, vol. 4(1), pp. 165-179, 2016.

[33] M.Y Cheng, J.S.Y. Ho, and P.M. Lau, "Knowledge sharing in academic institutions: a study of multimedia university Malaysia," Electronic Journal of Knowledge Management, vol. 3(7), pp. 313324, 2009.

[34] E. Ziemba and M. Eisenbardt, "Prosumers' eagerness for knowledge sharing with enterprises - a Polish study," Online Journal of Applied Knowledge Management, vol. 2(1), pp. 40-58, 2014.

[35] S. Wang and R.A. Noe, "Knowledge sharing: A review and directions for future research," Human Resource Management Review, vol. 20, pp. $115-131,2010$.

[36] H.-G. Lin, "Knowledge sharing and firm innovation capability: An empirical study," International Journal of Manpower, vol. 28(3/4), pp. 315-332, 2007

[37] S. Bagheri, R.J. Kusters, and J. Trieneken, "Business-IT alignment in PSS value networks - Linking customer knowledge management to social customer relationship management," in Proc. of 17th Int. Conf. on Enterprise Information Systems ICEIS, Barcelona-Spain, pp. 249257, 2015, http://dx.doi.org/10.5220/0005370002490257.

[38] M.C. Lee, "Business Intelligence, knowledge management and customer relationship management - Technological support in enterprise competitive competence," Business Intelligence: Concepts, Methodologies, Tools, and Applications, pp. 216-23, 2015, http://dx.doi.org/10.4018/978-1-4666-9562-7.ch011.

[39] P. Bharati, W. Zhang, and A. Chaudhury, "Better knowledge with social media? Exploring the roles of social capital and organizational knowledge management," Journal of Knowledge Management, vol. 19(3), pp.456-475, http://dx.doi.org/10.1108/jkm-11-2014-0467.

[40] A.Y.K. Chua and S. Banerjee, "Customer knowledge management via social media: The case of Starbucks," Journal of Knowledge Management, vol. 17(2), pp. 237-249, 2013, http://dx.doi.org/10.1108/13673271311315196.

[41] D.P. Ford and R.M. Mason, "A multilevel perspective of tensions between knowledge management and social media," Journal of Organizational Computing and Electronic Commerce, vol. 23(1-2), pp. 7-33, 2013, http://dx.doi.org/10.1080/10919392.2013.748604.

[42] C. Heller-Baird and G. Parasnis, "From social media to social customer relationship management," Strategy \& Leadership, vol. 39(5), pp. 30-37, 2011, http://dx.doi.org/10.1108/ 10878571111161507

[43] M. Levy, "WEB 2.0 implications on knowledge management," Journal of Knowledge Management, vol. 13(1), pp. 120-134, 2009, http://dx.doi.org/10.1108/13673270910931215.

[44] Z. Zhang, "Customer knowledge management and the strategies of social software," Business Process Management Journal, vol. 17(1), pp. 82-106, 2011, http://dx.doi.org/10.1108/14637151111105599.

[45] Å. Fast-Berglund and E. Blom, "Evaluating ICT-tools for knowledge sharing and assembly support," in Proc. of the 5th Int. Conf. on Applied Human Factors and Ergonomics AHFE 2014, T. Ahram, 
W. Karwowski and T. Marek, Eds., pp. 2734-2742, Krakow, Poland, 19-23 July, 2014.

[46] W. Jiebing, G. Bin, and S. Yongjiang, "Customer knowledge management and IT-enabled business model innovation: A conceptual framework and a case study from China," European Management Journal, vol. 31(4), pp. 359-372, 2013, http://dx.doi.org/10.1016/ j.emj.2013.02.001.

[47] M.A. Razzak, R. Ahmed, "Knowledge sharing in distributed agile projects: techniques, strategies and challenges," in Proc. of the 2014 Federated Conf. on Computer Science and Information Systems, pp. 1431-1440, 2014, http://dx.doi.org/10.15439/2014f280.

[48] S.C. Lee and R.S. Kelkar, "ICT and knowledge management: Perspectives from SECI model," The Electronic Library, vol. 31(2), pp. 226-243, 2013, http://dx.doi.org/10.1108/02640471311312401.

[49] I. Nonaka, "Dynamic theory of organizational knowledge creation," Organization Science, vol 5(1), pp. 14-37, 1994 http://dx.doi.org/10.1287/orsc.5.1.14.

[50] H. Jalonen, "Social media and emotions in organisational knowledge creation," in Proc. of the 2014 Federated Conf. on Computer Science and Information Systems, pp. 1371-1379, 2014 http://dx.doi.org/10.15439/2014f39.
[51] S. Okazaki, A.M. Díaz-Martín, M. Rozano, and H.D. MenéndezBenito, "Using Twitter to engage with customers: a data mining approach," Internet Research, vol. 25(3), pp. 416-434, 2015, http://dx.doi.org/10.1108/intr-11-2013-0249.

[52] M. Zembik, "Social media as a source of knowledge for customers and enterprises," Journal of Applied Knowledge Management, vol. 2(2), pp. 132-148, 2014.

[53] P.R. Hinton, C. Brownlow, I. McMurvay, and B. Cozens, SPSS Explained. East Sussex: Routledge, 2004.

[54] G. Smith, "Does gender influence online survey participation?: A record-linkage analysis of university faculty online survey response behavior," ERIC Doc. Reproduction Service, no. ED 501717, 2008. Available at: http://eric.ed.gov/?id=ED501717.

[55] E. Ziemba, Ed., Czynniki sukcesu i poziom wykorzystania technologii informacyjno-komunikacyjnych $w$ Polsce (in Polish), Warsaw: CeDeWu, 2015.

[56] E. Ziemba, "Factors affecting the adoption and usage of ICTs within Polish households," Interdisciplinary Journal of Information, Knowledge, and Management, vol. 11, pp. 89-113, 2016. 